\title{
Left atrial-esophageal fistula after atrial fibrillation ablation
}

\author{
Sheldon M. Singh MD, Isabelle Nault MD
}

\section{Left atrial-esophageal fistula is a deadly complication of atrial ablation}

Percutaneous and surgical ablation of atrial fibrillation is common worldwide. Because the esophagus is adjacent to the posterior wall of the left atrium, it is susceptible to thermal injury during ablation procedures. This may result in the development of a left atrial-esophageal fistula. Although case series have suggested a low prevalence $(<0.001 \%-1.2 \%)$ of this complication, ${ }^{1,2}$ mortality rates, including rates among patients who receive treatment, are high (67\%-100\%)., Procedural modifications have been introduced to reduce the likelihood of this complication, but this has not eliminated the risk. Periprocedural proton-pump inhibitors are advocated to minimize gastric acid exacerbation of thermal injury. ${ }^{5}$

\section{Computed tomography is the preferred diagnostic test}

Computed tomography of the chest with intravenous contrast is the preferred diagnostic test. ${ }^{6}$ Loss of clear delineation between the esophagus and adjacent mediastinal structures may be noted. The presence of intravenous contrast in the esophagus confirms a fistulous connection; this is a specific, but infrequent sign. Air in the mediastinum or cardiac chambers may be seen (Figure 1).

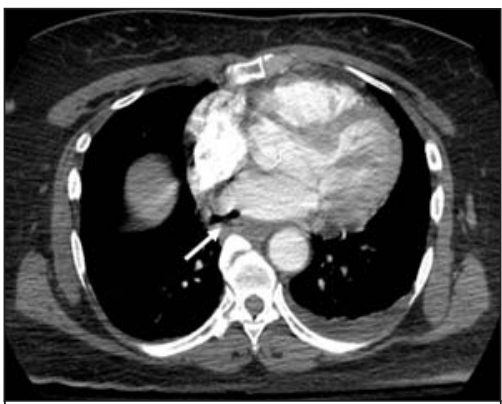

Figure 1: Computed tomography of the chest showing pneumomediastinum (arrow).
If a fistula is suspected, esophageal manipulation should be avoided

If a fistula is suspected, esophageal manipulation with transesophageal echocardiography, esophagogastroduodenoscopy, nasogastric tube placement or oral contrast imaging should be avoided because catastrophic embolism or bleeding may occur under increased esophageal pressure.

\section{References}

1. Cappato R, Calkins H, Chen S, et al. Prevalence and causes of fatal outcome in catheter ablation of atrial fibrillation. J Am Coll Cardiol 2009;53:1798-803.

2. Mohr FW, Fabricius AM, Falk V, et al. Curative treatment of atrial fibrillation with intraoperative radiofrequency ablation: short-term and midterm results. $J$ Thorac Cardiovasc Surg 2001;122:1239-40.

3. Siegel MO, Parenti DM, Simon GL. Atrialesophageal fistula after radiofrequency catheter ablation. Clin Infect Dis 2010;51:73-6.

4. Cummings JE, Schweikert RA, Saliba WI, et al. Brief communication: atrial-esophageal fistulas after radiofrequency ablation. Ann Intern Med 2006;144: $572-4$.

5. Zellerhoff S, Lenze F, Eckardt L. Prophylactic proton-pump inhibition after atrial fibrillation ablation: Is there any evidence? Europace 2011;13:1219-21.

6. D'Avila A, Ptaszek LM, Yu PB, et al. Left atrialesophageal fistula after pulmonary vein isolation: a cautionary tale. Circulation 2007;115:e432-3.

\section{A high index of suspicion is necessary after ablation}

Case series report the onset of symptoms between 3-41 days after ablation. ${ }^{3}$ Symptoms are frequently nonspecific. Dysphagia, odynophagia and gastrointestinal bleeding have been reported. ${ }^{3}$ Fever, leukocytosis and bacteremia may be present and misdiagnosed as endocarditis. ${ }^{3}$ Neurologic symptoms, including subacute emboli (septic, thrombotic or air), cerebritis or meningitis, have been reported in about $70 \%$ of cases.

\section{Prompt surgical intervention is essential}

The prognosis is dependent on prompt recognition and diagnosis. Once a fistula is identified, immediate surgical repair is required to improve survival and minimize morbidity. ${ }^{4,5}$ A multidisciplinary approach (preferably with a predefined plan) including cardiologists, cardiothoracic surgeons, gastroenterologists, radiologists, neurologists and infectious disease specialists is essential to optimize patient outcome.

Competing interests: Isabelle Nault has served as a consultant for Bayer and has received payment for lectures from Bayer and Sanofi. No competing interests declared by Sheldon Singh.

This article has been peer reviewed.

Affiliations: Division of Cardiology (Singh), Schulich Heart Centre, and Department of Medicine, Sunnybrook Health Sciences Centre, University of Toronto, Ont.; Division of Electrophysiology (Nault), Quebec Heart and Lung Institute, Laval University, Québec City, Que.

Correspondence to: Sheldon M. Singh, sheldon .singh@sunnybrook.ca

CMAJ 2013. DOI:10.1503/cmaj.121943 